\title{
ANAESTHETIC TIME/DOSE CURVES: VI. EXPERIENCES WITH DIAZEPAM ${ }^{*}$
}

\author{
Danielle Beaulieu, M.D., Marc Goyette, M.D., ANd Michael Kéfr-Szántó,M.D. $\nmid$
}

DiazepaM (Valium, Roche) is a popular tranquillizer with muscle relaxant properties. ${ }^{1}$ More recently it has been successfully used for premedication ${ }^{2,3}$ and in its parenteral form also for the induction ${ }^{4,5}$ and occasionally for the maintenance of anaesthesia, although in other centres diazepam was found to possess no anaesthetic properties. ${ }^{6}$

The drug does not fall under narcotic regulations. In ordinary doses, it will not affect the cardiovascular system. It produces little respiratory depression ${ }^{7}$ and minimizes nausea and vomiting on recovery from anaesthesia. These desirable properties appeared to warrant its more detailed study in a clinical situation. We undertook therefore to test the following null-hypothesis: "Intravenous diazepam is an effective supplement of nitrous oxide relaxant anaesthesia. Its distribution and inactivation are subject to the same limiting factors that determine drug requirements of other established intravenous anaesthetics."

\section{Material and Methods}

As in previous work, ${ }^{8-12}$ unselected adult patients from the surgical population of a 1000-bed teaching hospital were studied. They received routine premedication (meperidine and/or promethazine, together with a belladonna derivative). Endotracheal anaesthesia was induced and maintained with increments of intravenous diazepam, nitrous oxide, muscle relaxants, and mechanical hyperventilation. Data necessary for the construction of individual time/dose curves as set out earlier were recorded on the anaesthetic sheets along with sundry remarks about the course of anaesthesia and postanaesthetic recovery in these patients.

Forty-five out of forty-nine patients were successfully anaesthetized with this technique: in the remaining four, satisfactory anaesthesia required the addition of traces (up to 0.5\%) of halothane to the anaesthetic gases. While this change in technique was clinically of no consequence, it violated the experimental design, and we therefore attempted to prime the patients with diazepam before surgery, starting the night before and using the drug for premedication too, to the exclusion of all other drugs. ${ }^{4}$ Six patients were so treated and in five of them satisfactory anaesthesia could not be maintained without adding some additional agent in the course of surgery. This routine was abandoned as impractical and the clinical part of the study was ended.

- From the Department of Surgery, Université de Montréal, and the Anaesthesia Service, Hôpital Notre-Dame, Montreal 24. This study has been supported in part by a grant from Hoffmann-La Roche (Canada) Ltd.

†Service d'anesthésie, Hôpital Notre-Dame, Montréal 24, P.Q. 


\section{ResUlts}

The composition of our patient material is set out in Table I. Table II compares the time/dose curve constants of diazepam with the constants calculated previously for other intravenous anaesthetics. Figure 1 shows the scatter of individual time/dose curves, and in Figure 2 we compare the mean time/dose curves of different intravenous anaesthetics.

TABLE I

Summary of 45 Operations under Diazepam, Nitrous Oxide, and Relaxant ANAESTHESIA

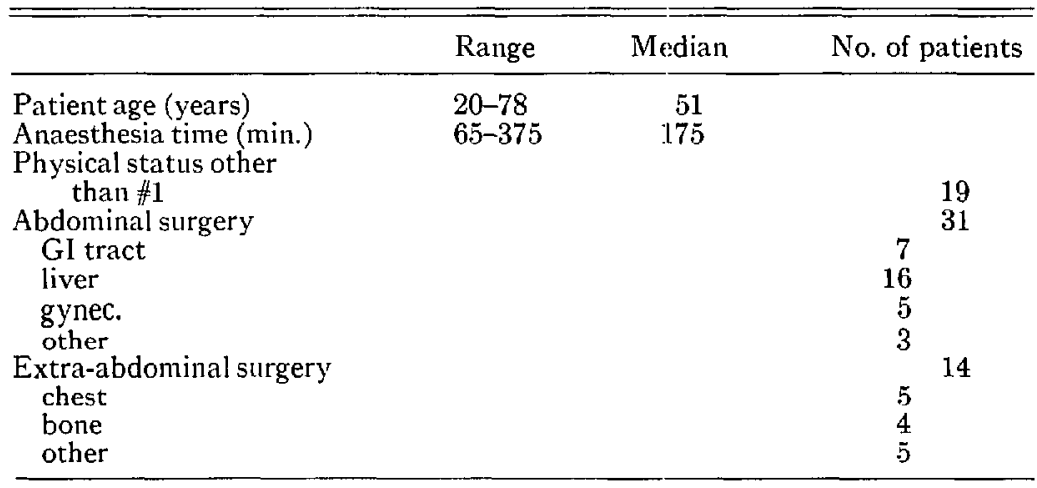

TABLE II

Comparison of Time/Dose Curve Constants with Various Intravenous Agents*

\begin{tabular}{|c|c|c|c|c|c|}
\hline Drug & $n$ & $\begin{array}{c}k \\
\left(\min ^{-1}\right)\end{array}$ & $\underset{\left(\mathrm{mg} . / \mathrm{m}^{2} / \mathrm{min} .\right)}{A}$ & $\begin{array}{c}B \\
\left(\mathrm{mg} \cdot / \mathrm{m} \cdot{ }^{2}\right)\end{array}$ & $\begin{array}{l}B / A \\
\text { (min.) }\end{array}$ \\
\hline Thiopental (8) & 104 & 0.073 & 1.75 & 298 & 170 \\
\hline Meperidine (9) & 23 & 0.065 & 0.244 & 55.3 & 227 \\
\hline Oxymorphone $(9)$ & 29 & 0.065 & 0.00356 & 0.663 & 184 \\
\hline Thiopental (in PN mixt.) (11) & 158 & 0.067 & 1.13 & 172 & 152 \\
\hline Droperidol (in NLA) (12) & $20+$ & 0.020 & 0.020 & 13.1 & 657 \\
\hline Diazepam & 45 & 0.077 & 0.112 & 19.9 & 178 \\
\hline
\end{tabular}

*Numbers in brackets refer to references at end of article.

†Confirmed since on 800 additional patients.

\section{Comment}

In the formal sense the null-hypothesis was not refuted: in roughly 90 per cent of our patients, anaesthesia could indeed be induced and maintained as proposed. The per- and postanaesthetic course of our patients was without incident, and their late recovery uneventful. One death occurred in the series, 28 days after surgery, adequately explained by the patient's preoperative condition and by complications not related to anaesthesia. The drug was put to a severe test in that it was used in long operations, frequently in patients with known cardiorespiratory ailments and from time to time under circumstances (aortic and carotid artery grafts) where even minor changes in oxygen delivery to the tissues could have 


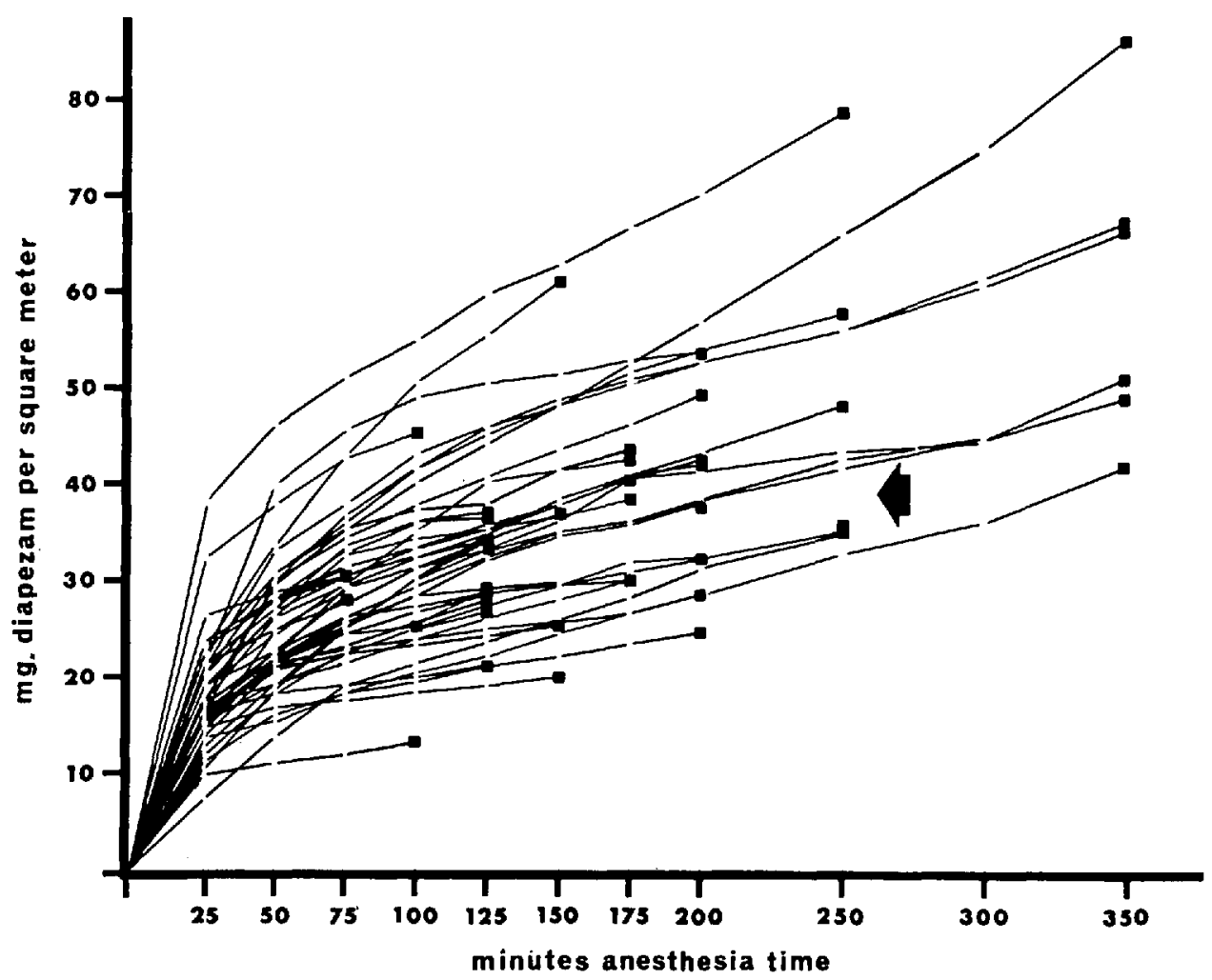

Figure 1. Time/dose curves of 45 patients with diazepam. Dots indicate the end of each anaesthesia. Arrow points to the separation between high-and low-consumption groups.

had grave consequences. The individual time/dose curves showed smaller scatter around the mean values than with many other intravenous drugs, yielding therefore a mean curve with tighter confidence limits than with meperidine or with neuroleptanalgesic drugs, for example. The mean curve can be superimposed on curves obtained with other agents when appropriate correction is made for the different potency of the drugs. This correction factor also serves to establish the relative potency of these drugs: in the present instance it shows diazepam to be 16.5 times as potent $(\mathrm{w} / \mathrm{w})$ as meperidine in supplementing nitrous oxiderelaxant anaesthesia.

For practical purposes, nevertheless, the answer to the question whether diazepam is an effective drug for the routine supplementation of nitrous oxiderelaxant anaesthesia must remain "almost, but not quite." In the first place, a failure rate of 10 per cent would be unacceptable to most anaesthetists, even though the failure implies nothing more serious than the need to add yet another drug to the anaesthetic. Then, injection of the drug in anything but very large veins resulted in pain (though not in persistent venous irritation). It required a certain finesse to keep the level of anaesthesia on an even keel. Secretions during and after anaesthesia were more abundant than we have recently come to expect. While recovery to the point of returning protective reflexes was fairly rapid, a 


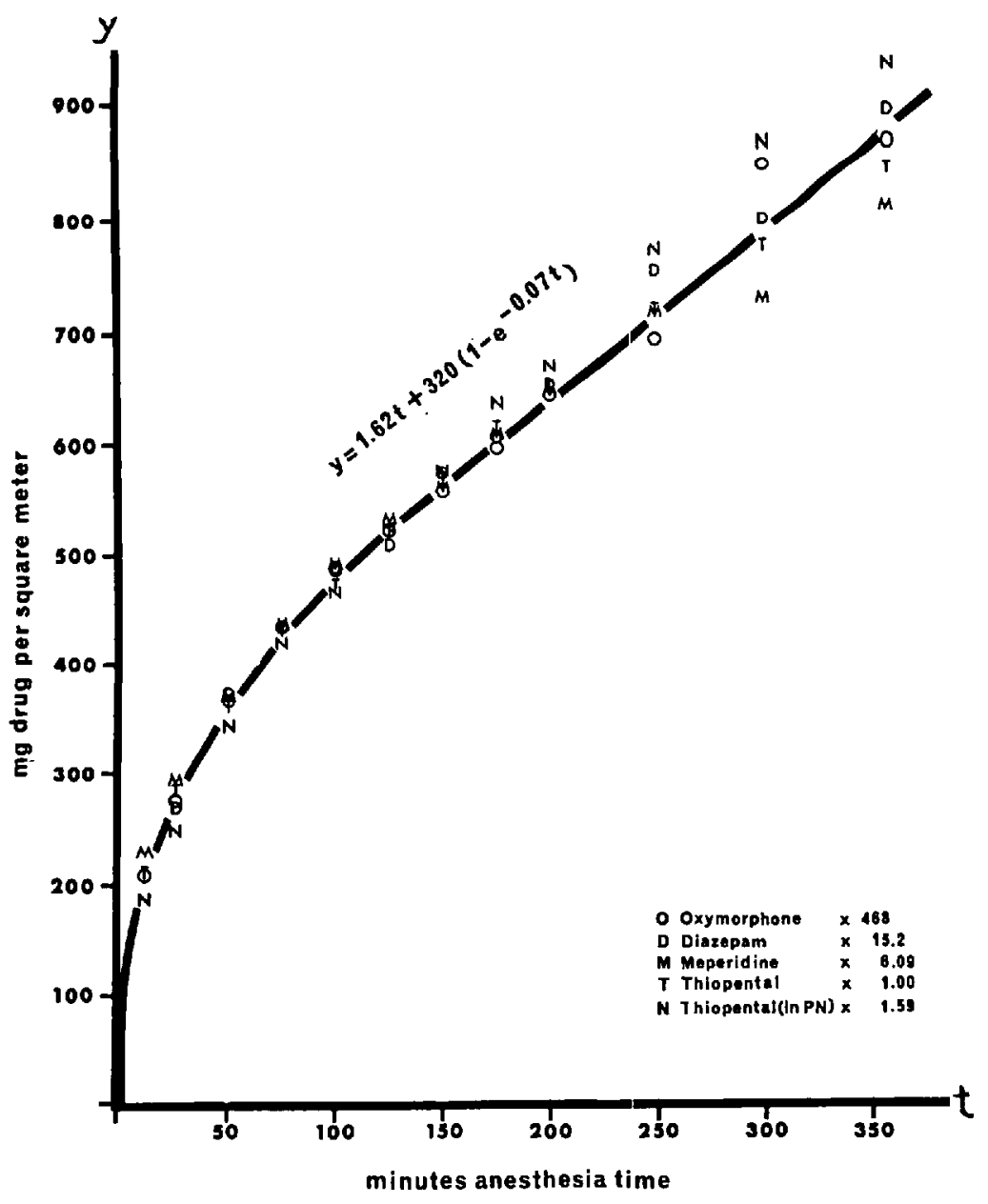

Figuhe 2. Relation between mean drug requirements $(y)$ and anaesthesia time $(t)$ for various intravenous anaesthetics. Numerical values adjusted to account for the different potency of each drug. The data represent about 350 individual time/dose curves.

good number of patients failed to progress quickly from there to the point of verbal arousal. The resulting delay in discharge from the recovery room has been a disadvantage in our hospital where more than 75 operations are performed each day. Some patients requiring particularly large doses of diazepam remained amnesic for the first 24 to 48 hours following surgery. Relaxant requirements in the entire group were significantly greater than in similar patients during previous similar investigations.

On the other hand, diazepam might be the intravenous anaesthetic supplement of choice under certain specific conditions:

1. For induction where the use of barbiturates is contraindicated (e.g. porphyria). Diazepam provides faster and smoother induction than most other drugs which we have studied in this fashion, and induction is unmarred by 
haemodynamic changes of any kind. Tracheal intubation can be achieved at a light level of anaesthesia, and the tube is well tolerated.

2. In patients with multiple drug sensitivities, diazepam has the unique advantage that it can be tested the night before surgery and applied with confidence the next day. This reduces the need to expose the patient to other potentially sensitizing drugs during anaesthesia.

3. In situations where it is necessary to maintain spontaneous ventilation during induction or maintenance (tension pneumothorax, facial and cervical wounds or deformities, etc.) diazepam provides quick, pleasant, and safe anaesthesia.

4. The tolerance of endotracheal tubes by conscious subjects is a far more stressful experience than tracheotomy. The advantages of this procedure in postsurgical states, trauma, tetanus, etc. for periods not exceeding 72 hours have been realized only since we succeeded in making these patients reasonably comfortable with Innovar. ${ }^{13}$ Diazepam with its relatively pure anxiolytic action promises to present an improvement over our earlier technique.

5. The drug appears to be uniquely suited to sedate patients during regional anaesthesia. This type of anaesthesia is usually selected in our hospital to accommodate patients who are afraid of general anaesthesia. It is also used to provide satisfactory operating conditions in positions presupposing elaborate general anaesthesia (e.g. jackknife) that would not be warranted by the nature of surgery per se. In this selected group, diazepam added up to 30 minutes of useful operating time in conscious patients when they became uncomfortable on the table or the effect of regional anaesthesia was wearing off before surgery was completed.

Additional observations, only peripherally relevant to the use of diazepam have also emerged from this study:

1. We have found it impossible to maintain satisfactory anaesthesia with nitrous oxide, relaxants, and hyperventilation (tidal volumes 25 to 50 per cent in excess of the values read from the Radford nomogram) when nothing but diazepam was used for premedication and supplementation during anaesthesia. This observation contrasts with claims by the Liverpool school that patients can be routinely anaesthetized by nitrous oxide, muscle relaxants, and hyperventilation alone. It would seem obvious from our observations that the effect of premedication must have played a greater part in the success of these anaesthetics than the authors would suggest.

2. Analysis of the 45 individual time/dose curves reveals once more that the scatter around the mean values does not correspond to the normal, Gaussian distribution: there is instead a fairly sharp division into a high- and a lowconsumption group. The division is complete by 100 minutes, and the patient population is divided among the two groups in much the same proportion as stated earlier:11 five high-consumption patients for every three low-consumption ones. Whether the patient belongs to one group or another appears to be independent of age, physical status, or type of surgery. Revision of other families of time/dose curves shows similar dichotomy (always involving the same proportion of subjects and the same relative value of drug consumption) when barbiturates, ${ }^{,}$ analgesics, ${ }^{\theta}$ tranquillizers, ${ }^{12}$ or combinations of various groups ${ }^{10,11}$ were employed. 
The literature, all of it non-anaesthetic, has been. reviewed in reference 11 ; it seems to indicate that the sensory input associated in one way or another with respiration plays a greater part in maintaining consciousness in 40 per cent of the hospital population than in the remaining 60 per cent. Manipulation of this input by even mild hyperventilation will consequently yield greater economy of anaesthetic consumption in the former group than in the latter. This knowledge should be of practical interest in the management of respirator patients and it might result in better prediction of anaesthetic requirements in long operations.

\section{SuMMarY}

The feasibility of supplementing nitrous oxide-relaxant anaesthesia with diazepam was investigated in a group of 55 patients. Satisfactory anaesthesia was achieved in 45 of 49 patients when conventional premedication was employed, but in only one of six when the premedication also was restricted to diazepam. In the remaining cases satisfactory conditions were achieved by adding traces of some additional anaesthetic. While practical corsiderations argue against the universal use of diazepam as an intravenous anaesthetic supplement, the authors list certain special indications where this might be the treatment of choice.

\section{RÉSUMÉ}

Notre investigation a porté sur la possibilité d'une anesthésie au protoxyde d'azote, myorésolutifs et diazépam chez 55 patients. Nous avons maintenu une anesthésie satisfaisante chez 45 sur 49 patients normalement prémédiqués, mais chez un seul sur six patients prémédiqués au diazépam. Dans les autres cas, des traces d'un agent complémentaire ont suffi à compléter l'anesthésie. On évoque des situations pratiques qui défavorisent l'usage courant du diazépam comme anesthésique intraveineux de supplément, et souligne les indications précises où il apparaît comme traitement de choix.

\section{REFERENCES}

1. Femi-Pearse, D. Experience with Diazepam in Tetanus. Brit. Med. J. 2: 862 (1966).

2. Tonnetta, F, J. Diazepam as a Preanesthetic Medication: A Double-blind Study. Anesth. Analg. Curr. Res. 44: 449 (1965).

3. Conmier, A. et al. Comparison of the Action of Diazepam and Meperidine in Anaesthetic Premedication. Canad. Anaesth. Soc. J. 13: 368 (1966).

4. McClish, A. Diazepam as an Intravenous Induction Agent for General Anaesthesia. Canad. Anaesth. Soc. J. 13: 562 (1966).

5. Stovner, J. \& Enderesen, R. Intravenous Anesthesia with Diazepam. Proc. II. Eur. Congr. Anaesth. 2: 223 (1966).

6. Urban, Bruno J.; Amaha, KeIsuke; \& Steen, Steven N. Investigation of 1,4-Benzodiazepine Derivatives as Basal Anesthetic Agents. Anesth. Analg. Curr. Res. 45: 733 (1966).

7. Sadove, M. S.; Balagot, R. C.; \& McGrath, J. M. Effect of Chlordiazepoxide and Diazepan on the Influence of Meperidine on the Respiratory Response to Carbon Dioxide. J. New Drugs. 5: 121 (1965).

8. KeÉrI-SzÁNTó, M. Drug Consumption during Thiopental-Nitrous Oxide-Relaxant Anaesthesia: The Preparation and Interpretation of Time/Dose Curves. Brit. J. Anaesth. 32: 415 (1960). 
9. KeÉri-SzÁntó, M. Anaesthetic Time/Dose Curves: II. The Limiting Factors in the Utilization of Intravenous Anaesthetics during Surgical Operations. Clin. Pharmacol. Therap. 2: 45 (1961).

10. Ké́RI-Szántó, M.; Knaff, M.; \& Rondeau, Y. Anesthetic Time/Dose Curves: III. The Interaction of Thiopental and Oxymorphone during Surgical Anesthesia. Clin. Pharmacol. Therap. 2: 441 (1961).

11. Ké́ri-SzÁntó, M. \& Leduc, C. Anesthetic Time/Dose Curves: IV. The Influence of Respiratory Parameters upon Intravenous Drug Requirements during Surgical Procedures. Anesthesiology. 23: 231 (1962).

12. Ké́ru-SzÁntó, M.; Telmosse, F.; \& Trop, D. Anaesthetic Time/Dose Curves: V. Data on Neuroleptic Drugs with Remarks about Their Action. Canad. Anaesth. Soc. J. 10: 484 (I963).

13. Aubry, U.; Denis, R.; Keéri-Szántó, M.; \& Parent, M. Factors Affecting Survival of the Geriatric Patient after Major Surgery. Canad. Anaesth. Soc. J. 12: 510 (1965). 